\title{
Una nueva especie de consagración real. La conversión intelectual del rey en el Livre des fais et bonnes meurs du sage roy Charles V
}

\section{Juliana Eva Rodriguez}

Instituto Multidisciplinario de Historia y Ciencias Humanas (IMHIClHU), Consejo Nacional de Investigaciones Científicas y Técnicas (CONICET), Argentina

julianarodrigueztemple@gmail.com

Recibido: 18/02/2020. Aceptado: 29/06/2020.

\section{Resumen}

En el Livre des fais et bonnes meurs du sage Roy Charles $V$, escrito en 1404 , se constata la ausencia de la unción entre los argumentos legitimadores de la monarquía francesa. Mientras la figura del rey ungido es silenciada, por el contrario, vemos aparecer con fuerza la figura del rey coronado. De este modo, la escritora altera la jerarquía de los ordines de consagración real al reducir la compleja ceremonia de consagración al rito de la coronación. Curiosamente, en los cinco capítulos que la autora dedica a describir el paso de la juventud a la madurez del rey, la coronación se inscribe dentro de una exposición sobre el ciclo natural de la vida de los hombres de tradición aristotélica medieval. No obstante, cabe preguntarse si la inserción de la consagración dentro del argumento etario puede considerarse como una simple casualidad o una mera cuestión de cronología. La ausencia de los atributos sagrados de la realeza provenientes de la leyenda monárquica, así como la omisión de toda mediación eclesiástica permiten suponer que la consagración propuesta por la autora es de una especie distinta al rito de pasaje que por medio de la unción asemejaba al monarca a un rex et sacerdos. Por consiguiente, este trabajo se propone analizar en qué consiste este nuevo tipo de consagración y la función que cumple en la teoría política de la escritora esbozada en el Livre des fais et bonnes meurs du sage Roy Charles $V$.

Palabras clave: Christine de Pizan, monarquía, Carlos V, consagración, Francia

\section{A New Type of Royal Consecration. The King's Intellectual Conver- sion in the Livre des fais et bonnes meurs du sage roy Charles $V$}

\author{
Abstract \\ The Livre des fais et bonnes meurs du sage Roy Charles V, written in 1404, shows the \\ absence of the anointing as a necessary element to legitimate the French monar- \\ chy. While the figure of the anointed king is silenced, we see, on the contrary, the
}


strong emergence of the figure of the crowned king. In doing so, the writer alters the hierarchy of the royal consecration orders by reducing the complex ceremony of consecration to the coronation rite. Curiously, within the five chapters dedicated by the author to describe the transition from the youth to the maturity of the king, the coronation is taken as part of the natural cycle of the life of men, according to the medieval Aristotelian tradition. However, the question arises as to whether the insertion of the consecration into the age- issue can be considered as a mere coincidence, or a simple question of chronology. The absence of sacred attributes of royalty typical from monarchical legends, as well as the omission of ecclesiastical mediations, allow us to suppose that the consecration proposed by the author is of a different kind than those rites of passage that, through anointing, assimilated the monarch with the figure of rex et sacerdos. Therefore, this paper aims to analyze the meaning of this new type of consecration and the role it plays in the political theory of the writer outlined in the Livre des fais et bonnes meurs du sage Roy Charles $V$.

Keywords: Christine de Pizan, monarchy, Charles V, consecration, France

\section{La ausencia del ungido}

No existen los reyes ungidos, sino los coronados. No será Clodoveo -el ungidosino Pharamond -el coronado- a quien Christine de Pizan presente como primer rey francés (De Pizan, 2009, pp. 41-42). Lejos de representar una mera alternativa estética, la historiadora Colette Beaune ha visto en dicha elección los comienzos de una laicización del mito de los orígenes nacionales del Reino de Francia (Beaune, 1985, p. 340). A diferencia de Clodoveo, la figura de Pharamond encarnaba una realeza que no era cristiana, pero que, sin embargo, era legítima. Ni paloma enviada, ni bálsamo celeste, ni arzobispo de Reims fueron necesarios para convertir al pagano Pharamond en el primer rey francés. Solo fue suficiente con que haya sido coronado por su pueblo como primer rey de Francia (De Pizan, 2009, p. 42). Si por las venas de Francion, Marcomir y Príamo corría por igual la sangre de la realeza troyana, dichos personajes míticos jamás abandonarían la categoría de jefes migratorios. Entre ellos, solo Pharamond ostenta el título de rey y este hecho se produce a partir de su coronación en territorio francés: "auquel duc Priant succeda Marchonieres, qui engendra Pharamon, que yceulx couronnerent à premier roy de France" (De Pizan, 2009, p. 42). Lo que este acto simbolizaba era la simbiosis entre persona real, dinastía, territorio (Galia) y pueblo (comunidad política) o, asimismo, los deberes del rey frente al reino, entendido este como una entidad humana y geográfica definida (Rodriguez, 2016a). Hasta aquí, lo que se refiere al plano del mito. ¿Pero cuáles eran sus implicaciones en la teoría política de Christine de Pizan? ¿Cuál era el significado otorgado por la autora a la coronación de Carlos V?

Tanto Jacques Le Goff como Richard Jackson han visto en el ceremonial de consagración un rite de passage que transformaba al rey en un hombre nuevo dotado de los atributos necesarios para cumplir plenamente con las obligaciones que Dios le había encomendado. Ambos autores coincidieron en señalar que la consagración no era una condición necesaria para la sucesión de un nuevo rey. No obstante, ninguno de los dos negó el carácter indispensable que para la realeza francesa tenía el ceremonial. Para Le Goff, un rey no consagrado era un rey incompleto (2001, p. 20). Si bien al arribar a Reims el rey ya contaba con las dos primeras condiciones para ser rey -era un elegido de Dios y era rey por derecho hereditario-, le faltaba la tercera traditio, aquella de la consecratio. Era principalmente el rito de la unción realizado por el arzobispo de Reims-Ungo te in regem ("Par cette onction, je te fais roi")- lo que lo convertía verdaderamente en rey (p. 21). Palabras y actos marcaban 
la transmisión del poder de Dios al rey mediante la intercesión de la Iglesia. Por su parte, Jackson remarcaba que la consagración no hacía al rey, aunque sí constituía un fundamento de origen divino, ya que reforzaba el poder real al asociarlo a Dios y a la Iglesia:

Elle ajoutait au pouvoir séculier le pouvoir de Dieu par l'intermédiaire de l'Eglise. La royauté d'origine divine est inhérente à la royauté française, et c'est l'un des éléments essentiels du droit divin (Jackson, 1995, p. 247).

No existen dudas del interés de Carlos V por la liturgia de la consagración. A tales efectos, el rey manda a confeccionar un manuscrito con bellas miniaturas a fin de conservar para el futuro la liturgia de consagración de los reyes y reinas de Francia. Finalizado en 1365, este ordo es utilizado durante el ceremonial consagratorio de su sucesor, Carlos VI, en 1380. Este manuscrito fue expresamente encargado y supervisado por el mismo rey, quien le inscribe excepcionalmente su autógrafo cuya bella escritura refleja la de un letrado: "Ce livre du sacre des rois de France est à nous, Charles Ve de notre nom, roy de France, et le fimes coriger, ordener, escrire et istorier l'an MCCCLXV" (Demouy, 2016, p. 100). En dicha obra se deja ver claramente cómo la consagración confería un cambio de status. El despojo espectacular del rey, quitándose sus vestimentas habituales para transformarse en un hombre nuevo, marcaba un rito de pasaje. En el corazón del libro es la unción, con el aceite milagroso de la Sagrada Ampolla (representada diez veces), que hace del rey el individuo sacralizado más noble de toda la cristiandad, aquel rey "muy cristiano". Allí, el arzobispo prepara la unción mientras que el coro recuerda, mediante un responso, el milagro de la Sagrada Ampolla. Comienza luego el canto de las letanías que el rey y el arzobispo escuchan al pie del altar. Posteriormente, el rey se pone de rodillas delante del arzobispo, quien realiza con su pulgar una unción séptuple: sobre la cabeza (como en el caso de los obispos), sobre el pecho, entre los hombros, en cada uno de ellos y en la unión de los brazos, al tiempo que recita "Par cette onction d'huile sanctifiée, je te fais rois, au nom du Pére et du fils et du Saint-Ésprit" (Demouy, 2016, p. 125). Por el sagrado crisma, considerado milagroso, y por medio de la acción eclesiástica, el rey deviene un intermediario entre Dios y el pueblo. Del interés de Carlos V por esta liturgia nos habla asimismo el Traitédu sacre que el rey manda a confeccionar a Juan Golein como complemento de su traducción del Rational des Divins Offices del canonista Guillermo Durand.

Curiosamente, contra todas estas evidencias, Christine no parece atenerse a dichos argumentos ni ser lo suficientemente receptiva a la tradición del sacre royal. Por empezar, el título del capítulo del Livre des fais destinado al tema en cuestión era de por sí sugestivo: "Cy dit, le couronnement du roy Charles, et comment, tost après, prist à suivre la rigle de vertu" (De Pizan, 2009, p. 46). Este cambio que la escritora operaba dentro de la jerarquía de los ordines del sacre royal, es decir, el hecho de reducir la consagración al rito de la coronación, se repite a lo largo del libro y es una constante en toda la obra literaria de la autora (Autrand, 2009, p. 352). Esta actitud frente a la consecratio, indudablemente, se encuentra en consonancia con la postura de Christine en torno a la leyenda monárquica. Al respecto, existe en el pensamiento político de la autora una remarcable ausencia de los atributos sagrados de la realeza provenientes del ciclo de Clodoveo (Beaune, 1985, pp. 55-82). Por lo demás, no existe descripción alguna del ceremonial, lo que no puede adjudicarse a la parquedad literaria de la escritora al momento de describir los ceremoniales. Los relatos de las chevauchées, el ritual mortuorio de la reina y el bautismo de Carlos VI son ejemplos de que Christine no renegaba de los detalles si los consideraba necesarios ${ }^{1}$. Para el caso de la coronación, los datos se reducen a la datación del evento: 
Selons le triomphe, par ancien et redevable usage, le jour de la Trinité, en l'an de grace mil trois cens soixante et IIII, de sa nativité XXVIle, cestui sage Charles roy quint du nom, fu coronné (De Pizan, 2009, p. 46).

No obstante, más allá del carácter sucinto del relato, es más bien el lugar que ocupa la consagración dentro del conjunto de la obra lo que parece estar sugiriendo más de lo que cualquier descripción del ceremonial podría haberlo hecho. En principio, porque la localización del argumento parece estar indicando dos cuestiones. Primero, el desdén que la escritora manifestaba por el milagro y los fenómenos del orden de lo maravilloso. Segundo, una interpretación innovadora de la consagración, como fenómeno exclusivamente político.

En primer lugar, la coronación del rey se inscribe dentro de una exposición sobre el ciclo natural de la vida de los hombres. Después de las filiaciones -mítica y bíblica- de la monarquía hereditaria, Christine dedicaba los cinco capítulos posteriores a abordar las distintas edades del hombre según los humores hipocráticos y dentro del marco de referencia aristotélico propio de los espejos de príncipe, como es el caso del De regimine principum de Egidio Romano ${ }^{2}$. Interesada en el paso de la juventud a la madurez, la autora recurría a la filosofía y medicina de los antiguos, canalizando las máximas generales a través de la materia ejemplar bíblica y pagana (Ribémont, 2000; Rodriguez, 2019). En su razonamiento, la juventud aparecía como aquel terreno signado por los apetitos naturales de los hombres, repleto de excesos y vicios y marcado por la ausencia de razón. Por el contrario, la madurez, despojada de aquella pasión irreflexiva, aparecía dirigida por la razón del hombre sabio: "la perfection du sens humain ne doit estre prise fors en aage de discrecion, ouquel temps homme est appellé vir" (De Pizan, 2009, p. 43). A su vez, la plenitud de la sabiduría se alcanzaba una vez pasado el hombre la cincuentena:

Or, nous convient parler du temps que le fruit est meur, cueilli et mis en sauf pour en proffitablement user; ce est adonc que l'omme a ja passé .L. ans; lors cellui qui est de sain et sage entendement à soy a ja recueilli les vertus du sentement de clere cognoiscence des choses qui savables lui peuent estre (p. 56).

Pero de pronto, este argumento de carácter general es interrumpido por un evento en la vida del rey, aquel de su consagración. Ese día, en el transcurso de la ceremonia, el rey pareció sufrir una especie de conversión que lo capacitó repentinamente para gobernar. Así, el delfín convertido en rey

fu enluminé de clere cognoiscence qui vraiement luy discerna le cler du trouble, le bel du lait, le bien du mal, par laquelle fu inspirez à droitte voie de en deboutant les jeuneces avuglées par flos d'ignorance (pp. 46-47)

A los veinticinco años, tras ser consagrado, Carlos parecía abandonar repentinamente los vicios de la juventud para convertirse en un hombre maduro, pleno de prudencia, capaz de distinguir lo claro de lo obscuro, el bien del mal. Distanciándose así de sus congéneres, aún enceguecidos por los vicios de la adolescencia, el delfín Carlos se aplicaría "à suivre la rigle de vertu" (p. 46).

De acuerdo a los esquemas etarios, Carlos V murió mucho tiempo antes de alcanzar la edad cumbre de la sabiduría y era aún joven al momento de ser coronado. Dentro de las categorías bajomedievales, la edad de la pubertad solía extenderse hasta los

2 Para la organización de la educación en periodos de siete años según Aristóteles, véase Política 1335b. En cuanto a Egidio Romano, puede consultarse la rúbrica de la segunda parte de Li livres du gouvernement des rois: a XIIIth Century French Version of Egidio Colonna's Treatise De Regimine Principum (Molenaer, 1899). 
25 años de edad y en la alta aristocracia, hasta la treintena. Sin duda, la idea de un hombre maduro a los 50 años de edad, tal como proponía la autora, podía resultar exagerada si se tiene en cuenta el escaso promedio de vida de la época. No obstante, el tópico de la perfecta madurez debe entenderse dentro del ideal de hombre sabio y prudente ligado a la noción de experiencia que defendía la escritora.

\section{La juventud en el ciclo natural de la vida de los hombres}

Carlos V jamás llegó a la cincuentena, pues murió antes de alcanzar la plenitud del hombre sabio el 16 de septiembre de 1380 . A su vez, aún era joven cuando fue coronado. ¿Cómo se explica entonces la insistencia de la escritora en adelantar la madurez del rey? ¿Por qué se volvía necesario hacer del delfín un hombre maduro al momento de su consagración? Consideramos que el hecho de que la escritora se refiriese a la coronación antes que a la unción no solo se explica por su escepticismo respecto al milagro de la Sagrada Ampolla sino por su interés en destacar el aspecto político de la ceremonia. Al ceñirse la corona, el monarca ingresaba al officium regis.

Desde esta perspectiva, ¿podía un rey gobernar con el carácter de un joven? En el modelo teórico de la escritora, la juventud aparecía como un estado bestial de humores desordenados y dirigido por los instintos naturales:

environ l'aage de son adolescence, adont n'est nulz qui peust comprendre les divers mouvemens qui en cellui corps sont compris, lequel, comme passionné d'appetit sanz ordre, par inclinacion naturele non cognoiscent encore la lime et correction de raison (De Pizan, 2009, pp. 48-49)

Aunque de carácter universal, puesto que este estado no reparaba en categorías sociales alcanzando indistintamente tanto al noble como al humilde, la juventud se presentaba especialmente peligrosa para los príncipes. A continuación, la metáfora alquimista del fuego, el azufre y el fresno en un mismo recipiente reforzaba la idea que hacía de los príncipes los individuos más perjudicados por las pasiones juveniles:

et plus es princes et es poissans que es moyens ne es mendres; la cause si est pour l'assemblement de jeunece, oisiveté et poissance ensemble, qui est comme feu, souffre et esche en un vaissel (p. 51).

El orgullo y los apetitos naturales de un príncipe joven lo apartaban de sus responsabilidades de gobierno, convirtiéndose en presa fácil de las ambiciones de los hombres corruptos que lo incitaban al vicio con el objeto de satisfacer sus intereses personales (pp. 44-46).

Atendiendo a estas consideraciones, el futuro de un reino gobernado por un espíritu joven no se mostraba demasiado alentador. Asimismo, la escritora lo consideraba una maldición: "Si ne fu mie dit sanz cause "Maulditte est la terre dont le prince est enfent" (p. 51). En rigor, dicho pesimismo se comprende si se tiene en vista la concepción de la función real elaborada por la autora a lo largo de la obra. En tanto ejercicio de gobierno prudente y responsable, el oficio regio absorbía al individuo exigiéndole la más absoluta dedicación. De acuerdo a estos parámetros, se observa lo alejado que estaba el carácter individualista del joven respecto a la abnegación requerida por el servicio regio. Un rey con el espíritu de un joven venía a derribar en lo inmediato la razón de ser del officium regis. La defensa del bien común no podía ser la meta de quien priorizase sus intereses y deseos particulares, pues el príncipe orgulloso era la contracara del servicio a la Corona. De ahí que al momento de ser coronado, el rey 
debía asumir como hombre maduro, a pesar de que su edad no lo acreditase. ¿Pero cómo justificar la conversión del rey? ¿Cómo explicar el quiebre de la ley natural que esta última implicaba? Bien podría atribuirse la causa al milagro de la Sagrada Ampolla si se tratase de un argumento postulado por escritores que, como Jean Gerson y otros, creían en los signos celestiales de la unción ${ }^{3}$. No obstante, no parece ser el caso de Christine, quien era impermeable a la leyenda monárquica y a todo atributo otorgado por el ritual eclesiástico. En todo caso, si existía un elemento religioso en el episodio de la coronación, era aquel de la gracia divina ${ }^{4}$.

\section{El rey entre los elegidos}

De acuerdo a la teología de la gracia desplegada por la escritora, esta era un atributo que, aunque se manifestase en ocasiones precisas, acompañaba de manera permanente a los reyes franceses desde su nacimiento hasta su muerte. Así, Carlos V (segundo Moisés) y Carlos VI (segundo David) (De Pizan, 2009, pp. 42-43 y 140-141) habían nacido bajo el signo de la gracia divina, que los acompañaría por el resto de sus vidas:

D’ycelle ditte noble lignée Dieu, ameur du tres crestien peuple françois, pour la reparacion, confort et preservacion dudit lieu (...) tout ainssy comme jadiz donna Moyse, né de nobles parens, ou temps de l'adversité d'Egipte, aux enfens d'Israel (...) voult la divine Providence faire naistre de parens solemnelz et dignes (...) ycelluy sage Charles, lequel fu le.LVle. roi de France, puis le roy Pharramont dit dessus (pp. 42-43).

Carlos V y sus descendientes formaban parte de un mismo linaje de reyes "muy cristianos" que se extendía de Pharamond en adelante y que venía gobernando desde antaño. No obstante, aunque nacido bajo el signo de la gracia divina, el rey no estaba exento de los pecados propios de la infancia. De ahí el interés de la autora por evadir dicha etapa de su vida sin ahondar en detalles 5 .

Sin duda, la gracia era el elemento que le permitía al rey quebrar las leyes de la naturaleza y adquirir ciertas ventajas sobre el resto de sus congéneres. Sin embargo, nada más erróneo que ver en ella un monopolio real, ya que existían otros hombres que, sin ser príncipes o reyes, habían sido también iluminados "Et pareillement sont à mains influées telles graces" (p. 57).

Así, inscribiéndose nuevamente en el ciclo natural de la vida de los hombres, la escritora daba a conocer los dos casos en que se quebraba la ley natural. El primero incluía a aquellos hombres viejos que a pesar de alcanzar la edad propia de la madurez continuaban gobernados por los vicios de la juventud. El segundo era el de aquellos jóvenes que esclarecidos por la gracia divina estaban llenos de virtud de manera prematura contando con la razón como guía de sus conductas ${ }^{6}$. Por ende, si bien la mayoría de los jóvenes carecían de las virtudes necesarias para gobernar, existía ese otro grupo de jóvenes -los "esleus"- que, esclarecidos por la gracia divina, habían escapado a los vicios de la juventud y caminaban por la senda de la virtud. Sin duda,

3 Para las innovaciones introducidas en el ordo por Carlos V, véase Demouy (2016).

4 “La pensée de Christine, rappelons-le, doit moins aux croyances de la religion royale qu'à la théologie de la grâce" (Autrand, 2009c, p. 253).

5 “de la quelle chose grant narracion faire n'est mie neccessaire, ne a propos singulier où je vueil tendre, qui n'est fors seulement trattier de ce qui touchera ses vertus et estat en sages et bonnes meurs et autres particularitez, lesquelles assez sont sceues par le commun ordre du noble estat roial de France ne seroient fors prolixitez non neccessaires, si me passeray de son enfence assez legierement" (De Pizan, 2009, p. 43).

6 "ne aussi de ceulx qui grant aage ont accompli sanz la cognoiscence de vertu ou prudence, comme assez en soit d'anciens sanz sens, et d'autres jeunes assez d'aage et moult reemplis de vertus et savoir” (p. 57). 
Carlos V entraba dentro de este grupo de jóvenes elegidos "si comme fu le sage roy Charles dont nous traitons, qui, mesmes en très jeune aage, voult cognoistre les effetz de vertu, qui estoit don de Dieu par dessus nature" (p. 57).

Este desfasaje en la naturaleza, propiciado por la gracia que colocaba a estos jóvenes por fuera de las conductas normales esperadas para su edad, se ponía en evidencia a través de la exclusión que sufrían por parte de sus congéneres, quienes por considerar extraños sus comportamientos, se burlaban de ellos tachándolos de locos e insensatos:

si comme par expérience le veons avenir en yceulx jeunes qui sont desvoiez faire desrision de leur compagnons se ilz les voient retrais par grace de Dieu des folies susdittes, ou que autres jeunes ne soient vaguans en la voie de dissolucion comme eulx, ilz les reputent folz et chétifs (p. 50).

No obstante, para Christine estas burlas no eran más que elogios a oídos del sabio "blasme de telz sont aux oreilles des sages moult grans louanges" (p. 50). Por lo demás, si estos jóvenes persistían en el camino de la virtud, con el paso del tiempo y alcanzada la madurez sus aptitudes se multiplicarían con creces:

Et pareillement sont à mains influées telles graces; mes n'est mie doubte que, se telz hommes, ainsi esleus peuent vivre jusques en aage de meureté, que à cent doubles en eulx est creue la perfection de leur graces (p. 57).

La gracia aparecía como el atributo que predisponía a un determinado hombre a introducirse en la escuela de la virtud y le permitía escapar de la ley natural que hacía del cuerpo joven la cuna de los vicios y las pasiones irreflexivas. No obstante, el resto dependía de ellos, incluso, y de manera especial, en el caso del rey. Por lo tanto, ¿en qué se basaba este deseo o predisposición para conocer los efectos de la virtud? O lo que es lo mismo, ¿a qué se refería la autora cuando hablaba de una virtud que podía multiplicarse -"à cent doubles"- con el paso de los años?

\section{Teoría y experiencia en la escuela de la virtud}

En rigor, la "école de la vertu" (De Pizan, 2009, p. 57) era el proceso de aprendizaje que el joven debía transitar para volverse un hombre maduro. Siguiendo los postulados de la Metafísica en torno a la unidad de la cosa con su principio primero "chascune chose désire estre conjoincte avec son principe" (p. 48), el alma, presa del cuerpo "vaissel composé de grosses et materieles substances" (p. 48), se uniría con la razón o el intelecto gracias al trabajo del tiempo ${ }^{7}$. En este sentido, el paso de la juventud a la madurez no era un acto repentino sino que, por el contrario, se producía a través de un proceso paulatino de formación "par procès d'ans" (p. 48). Esta idea del cuerpo joven como materia moldeable se basaba en el concepto de tabla rasa atribuido a Aristóteles, según el cual el entendimiento era como una tabla rasa en la cual se podía escribir y grabar todo aquello que se quería ${ }^{8}$. La educación era el medio para torcer la predisposición natural de todo joven hacia el vicio y reconducirla por el recto camino

7 "car, si, comme dit Aristote, ou primier de métaphisique, chascune chose désire estre conjoincte avec son principe, car en ce est le terme de toute matière créé, ycelle ame est translatée ou corps, lequel est vessel composé de grosses et matérielles substances, qui rent l'esperit empêché et comme lié des opéracions intellectives, auquel, par procès d'ans, convient attendre temps et aage jusques l'instrument par où il doit ouvrer ait par ordre de nature pris convenable croiscence, ains que les vertus de l'ame puissent, se petit non, monstrer l'œuvre de sa soubtilleté" (De Pizan, 2009, p. 48). Al respecto, véase Aristóteles, Acerca del Alma, $430 a$.

8 "tout ainsi comme une table rese, comme dit Aristote, en laquelle on peut escripre et figurer ce que l'en veult, si comme nous veons es enfens que l'en fait apprendre tel art comme on veult” (De Pizan, 2009, p. 48). 
de la razón. Por ende, el joven príncipe debía educarse para reinar. Pero si la materia educativa ya era bien conocida gracias a los espejos de príncipes, lo interesante en Christine fue su hincapié en el carácter dual del aprendizaje. En primer lugar, correspondía al príncipe la educación erudita clásica del trivium et quadrivium a fin de dotarlo de los conocimientos necesarios para el oficio regio?. Asimismo, el estudio servía para combatir la pereza y alejarlo del ocio pernicioso que se le ofrecía a todo joven, en especial a aquel cuyo rango le permitía satisfacer las fantasías juveniles (pp. 44-46). De ahí que fuese responsabilidad de los padres apartarlo de las malas compañías que, usando al príncipe como rehén de sus ambiciones personales, lo alejaban del camino de la virtud ${ }^{10}$. En su lugar, siguiendo el hábito de los Antiguos, debían colocarse honestos y sabios consejeros así como también expertos versados en las distintas ramas del saber, que transmitiesen sus conocimientos al futuro soberano.

Sin embargo, y aquí radica lo fundamental del pensamiento de la autora, la educación formal resultaba insuficiente si no se la complementaba con un tipo de aprendizaje práctico forjado en la experiencia, ya que para Christine "cellui qui y est prudent doit estre creu en son experience" (p. 56). Ateniéndose a la definición aristotélica y ciceroniana, la escritora veía en la experiencia la base de la prudencia, virtud directriz del ejercicio de gobierno (Rodriguez, 2016b). Por ende, no es casual que la escritora invocase durante la consagración de Carlos $\mathrm{V}$ las pruebas necesarias que la providencia había enviado al delfín a fin de que pudiese experimentar la ardua tarea de gobernar:

par grâce de Dieu et especial don de divine informacion, par les bateures infortunées, ja longtemps, receues en son royaume, par guerres, pertes excessives et tribulacions infinies, qui souvente foiz peuent estre proffitables et salutaires aux vagues humains à cause de adverticence de leur vie inique et recognoissance de leur créateur, fu enluminé de clere cognoiscence (De Pizan, 2009, p. 46).

En este sentido, el rey iluminado por la gracia divina durante su ceremonia de consagración era un hombre ya experimentado, al cual la misma providencia había puesto a prueba desde tierna edad. Ciertamente, aunque Christine no desarrollase en dicho capítulo las "bateures infortunées" y las "tribulacions infinies" que había sufrido el delfín antes de su coronación, estas pueden encontrarse desplegadas a lo largo de la obra y en el corpus textual de la escritora, dado que eran de común conocimiento de sus contemporáneos. ¿Cuáles habían sido entonces las tribulaciones sufridas por el delfín en su juventud que habían contribuido a forjar su experiencia de gobierno? Sin duda, en aquellos años el joven príncipe vio cernirse sobre el reino, con una furia poco antes vista, a los tres jinetes del apocalipsis: guerra, hambre y peste (Favier, 1980, p. 179-180).

Ante todo, la guerra. Con más de treinta años de historia y peleada por completo en territorio francés, la guerra se había convertido en un modo de vida, una forma de existencia humana que distaba mucho de las esporádicas batallas feudales (Favier, 1980, p. 99-100). Este siglo que Jean Favier (1980, p. 179) acordó en llamar "un siglo de psicosis de guerra" venía acompañado de la peste, el hambre, la escasez y el estancamiento de los precios del trigo, todo lo cual repercutía en el malestar y la incertidumbre de la población. Entrada la segunda mitad del siglo XIV, el panorama estaba lejos de ser alentador: merma poblacional, tierras devastadas, descenso de la producción agrícola y artesanal, cese parcial de los intercambios comerciales, desempleo en las áreas rurales

9 Sobre la educación que Juan II proporcionó a su hijo, el futuro Carlos V, véase De Pizan, 2009, p. 43-44: “Si n’en diray autre chose, excepté que la sage administracion du père le fist introduire en lettres moult souffisamment et tant que competemment entendoit son latin, et suflisamment sçavoit les rigles de gramaire; laquelle chose pleust à Dieu que ainsi fust acoustumé entre les princes!".

10 "Si ton œil te scandalize, si l'oste de toy pour oster toute fole memoire, chaça d'environ soy tous les folz procureurs, administrateurs et adnonceurs des foles jeuneces passées” (De Pizan, 2009, p. 59). 
y conmoción monetaria. Frente a esto se encontraba una monarquía asfixiada por los gastos de guerra. Las derrotas francesas que se sucedían unas tras otras en el campo de batalla evidenciaban la fragilidad del poder real. Como corolario, la movilidad de las lealtades empeoraba el cuadro de una monarquía ya de por sí debilitada ${ }^{11}$.

Definitivamente, la juventud del delfín Carlos quedó sellada bajo el peso de estos tiempos turbulentos. No obstante, fue el año de 1357 el momento que marcó el rumbo del futuro rey de Francia. Tras el desastre de la batalla de Poitiers, el vacío mismo: "plus de roi, plus d'armée, plus d'argent", en la célebre frase de Joseph Calmette ${ }^{12}$. Tras la derrota, las tropas francesas abatidas y desmoralizadas en el campo de batalla veían cómo su rey y los nobles más ilustres, como Felipe de Orleans, eran capturados y tomados como rehenes por el adversario inglés. Ante esta situación, un joven de tan solo dieciocho años se veía impelido a asumir el mando de manera prematura para afrontar la más grave crisis política que la monarquía hubiera conocido desde 1314, tras la muerte de Felipe el Hermoso. Completamente solo, con gran parte de la nobleza del reino capturada, el delfín recibía de su padre cautivo una única directiva: liberarlo del yugo inglés ${ }^{13}$. Una vez dada la orden, el rey se dedicó a disfrutar de los placeres y convites de la corte inglesa. Sobre el grato cautiverio de los nobles franceses en la corte del rey inglés, Christine se explaya tomando como ejemplo la estadía del duque de Borbón, cuñado del delfín Carlos:

En Angleterre fu prisonnier avec le roy Jehan, ouquel pays si gracieusement se contint, que mesmes au roy Edouart, à ses enfens, et à tous tant plaisoit, qu'il luy estoit abandonné d'aler esbatre et jouer partout ou il luy plaisoit; et, à brief parler, tant y fist par son sens, courtoisie, peine et porchas (...) En Angleterre, moult bien jousta, car bel jousteur estoit, et avec tous ses autres biens estoit vaillant et chevalereux (De Pizan, 2009, p. 133).

Sin embargo, mientras el rey y los príncipes de sangre parecían esperar sin preocupaciones por su rescate, que, lejos de avergonzarlos, los enorgullecía por entrar dentro de los códigos de honor vasallático, el joven delfín afrontaba los problemas de un reino. Frente al malestar social y con un tesoro vaciado, el delfín se vio ante la magna tarea de poner a funcionar la maquinaria fiscal de la monarquía para pagar el rescate. Pero mientras su objetivo estaba puesto en la liberación de su padre, estallaron una serie de cuestionamientos al poder central, latentes desde décadas atrás.

En primer lugar, el delfín Carlos debió afrontar la rebelión de los estados generales, que al mando de Robert le Coq y Étienne Marcel -líderes de la alta burguesía- tomaron París y llegaron a proponer una especie de monarquía bajo control o monarquía tutelada (Favier, 1980, p. 230; Autrand, 1994, pp. 236-272; Bove, 2009, pp. 124-153). A su vez, entre las demandas de los revoltosos estaba la liberación de Carlos el Malo, el heredero capeto con pretensiones al trono de Francia, quien además había sido el apoyo económico y político de la revuelta. Estos acontecimientos demostraron al delfín cuán lejos estaba el poder monárquico de ser incuestionable. En dicho año, el nuevo regente hubo de enfrentar a los Jacques, una serie de levantamientos campesinos de carácter antinobiliario y antifiscal vinculados a las tierras más ricas del bassin

11 Existen varios capítulos en el Livre des fais que se extienden sobre el tema de las traiciones, aunque la escritora se centre en la actitud del monarca antes que en aquella de los traidores. Al respecto, pueden consultarse los capítulos XXIV, XXXI y XXXV del Libro I del Livre des fais (De Pizan, 2009, pp. 75-77; 90-92; 99-101).

12 Sobre la batalla de Poitiers, la escritora se refiere a ella en varios capítulos. Por ejemplo, al momento de hablar de la valentía del duque de Borgoña durante la captura de su padre Juan II, hecho que le valió el apodo de Felipe "el Atrevido". Al respecto, véase el capítulo XIII del Libro II del Livre des fais (De Pizan, 2009, pp. 128-132).

13 Desde su cautiverio, Juan II se había limitado a dar a sus súbditos tan solo un mensaje de consuelo: Vous avez perdu votre père; y a continuación, la orden para que contribuyesen al pago de su rescate. Al respecto, véase Favier (1980, p. 225). 
parisien: Beauvaisis, Soissonnais y Brie (Favier, 1980, p. 230; Autrand, 1994, pp. 318-330; Bove, 2009, pp. 104-110). Como sustrato de estos conflictos ha de considerarse tanto el malestar como la incertidumbre social, productos de la continua guerra.

En rigor, existía algo peor que la guerra: sus secuelas. La desmovilización de las tropas se tradujo en la creación de una población desempleada proveniente de distintas partes del reino y de Inglaterra que vagaba a lo largo y ancho del territorio. A las compañías de routiers, formadas en principio por soldados desempleados, se les fue sumando un conglomerado de hombres de distintas categorías sociales que iban dejando tras su paso los destrozos de la rapiña, las violaciones y los saqueos hechos en las aldeas, pueblos y ciudades del reino ${ }^{14}$. Si a esta población desempleada la monarquía no conseguía reubicarla en algún sitio, aquel fenómeno que comenzaba a conocerse como la llamada "peste roja" amenazaba con volverse un problema estructural en el orden interno del reino, puesto que "encore chascun jour mengié et dévouré par grandes et excessives Compagnies esparses en divers lieux par son reaume" (De Pizan, 2009, p. 117).

Por último, el delfín Carlos tuvo que padecer la deshonrosa paz impuesta por los ingleses tras la firma del tratado de Bretigny ${ }^{15}$.

Ot regart sus le traittié de la paix, lequel avoit esté fait en manière de contrainte, pour le temps de trop grieve fortune, et pour obvier à plus grant inconvénient, lorsque son père, le roy Jehan estoit prisonnier en Angleterre; laquelle ditte paix ne luy estoit mie bien honnourable, ains moult au descroissement et préjudice de son reaume, seigneurie et poissance (p. 119).

Desde 1357 a 1360, con el reino decapitado tras la captura de Juan el Bueno, el poder de mando recayó sobre el primogénito Valois. Empujado por las circunstancias, el delfín se vio obligado a afrontar una serie de conflictos que acuciaban a la monarquía desde antes de Poitiers. Por cierto, el camino no fue fácil, ¿pero qué mejor entrenamiento para el ejercicio de gobierno podría habérsele presentado a este joven versado en ciencias pero carente de experiencia gubernativa? ¿Quién se atrevería a negar las adversidades que padeció el delfín al frente del reino mientras su padre, el rey, jugaba a caballero en la corte inglesa? Al fin y al cabo, el dominio de la ciencia política no era alcanzable por medio de las lecturas sino a través de la experiencia. Con el tiempo, el delfín se convertiría en un gran maestro de dicha ciencia:

sage maistre, et expert en ycelle science, laquelle la noblece de son courage, par prudence de son adveri entendement, lui apprenoit naturellement, sanz autre estude de lettreure aprise en ceste partie, car sa personne gouvernoit par pollicie très ordonnée, comme dit est (p. 68).

Si como afirmaba la escritora, citando a Polos d'Agrigente, "l'expérience fait l'art" (p. 51), podría pensarse que el delfín Carlos ya contaba con una gran experiencia en el poder para cuando ciñese la corona de Francia el día de su consagración ${ }^{16}$.

Si aquel día el rey fue esclarecido por la gracia, no obstante, fue la razón la que lo ayudó a comprender la amarga realidad por la que atravesaba el reino. Y si lo comprendió en aquella oportunidad fue precisamente porque le había llegado el momento

14 Sobre el tema de les compagnies, véanse Favier (1980, pp. 287-325) y Bove (2009, pp. 112-115).

15 Sobre los preliminares del tratado de Bretigny y sobre la paz de Calais, véanse Favier (1980, pp. 276-286) y Autrand (1994b, pp. 391-426).

16 “Au moment où la couronne lui échoit, Charles V a déjà l'expérience d'un pouvoir dont il est d'ailleurs investi, à titre de régent” (Favier, 1980, p. 56). 
de ejercer el poder y de aplicar las medidas necesarias para solucionar los antiguos problemas ${ }^{17}$. Empero este esclarecimiento por la gracia que entrañaba la adquisición del conocimiento y las habilidades prácticas para gobernar, lejos de ser un fenómeno repentino -como el acto milagroso de la unción- aparecía como resultado de una educación dual de carácter teórico y práctico. En este sentido, la consagración del rey en el pensamiento de Christine de Pizan combinaba dos razonamientos de distintas raíces: la metafísica aristotélica y la teología de la gracia.

En primer lugar, siguiendo los postulados de la Metafísica, la escritora hablaba del deseo de conocimiento que por naturaleza poseían todos los hombres, "tous hommes, par nature, savoir désirent; car, dit la glose: par appétit naturel l'entendement désire et couvoite sçavoir" (p. 204) ${ }^{18}$. No obstante, agregaba que lograban desarrollarlo únicamente aquellos esclarecidos por el don de la gracia divina. En rigor, solo los hombres que contasen con el don de un entendimiento perfecto podían alcanzar el conocimiento de las ciencias y la sabiduría. De ahí que de la conjunción de dichos elementos surgiese el hombre sabio: "Avec sapience et science est neccessaire don d'endement à perfaitte sagece, c'est assavoir homme sage" (p. 203). Si, como se ha visto, la gracia no era monopolio regio y, por esto mismo, existían varios hombres dotados de sutil entendimiento que les permitía multiplicar la virtud a temprana edad, solo el monarca se encontraba en la cima de estos agraciados por poseer el intelecto más perfecto: "Si povons de celluy Roy conclurre, que, entre les esleus estoit très souverain et suppellatif en haultece d'entendement" (p. 204). Un perfecto intelecto que le había permitido al monarca aprender las ciencias teóricas y especulativas pero también aquellas materias que por fuera de los libros se aprendían mediante la experiencia, como lo era, en gran parte, la ciencia política ${ }^{19}$.

En síntesis, la manifestación de la gracia durante la coronación del rey evidenciaba los primeros signos de madurez de aquel proceso de aprendizaje teórico y práctico al que el príncipe se había dedicado en su juventud. No sin razón la escritora recurre a la metáfora del campo minado con buenas semillas a fin de recordar que todo buen fruto no es más que el resultado de un arduo trabajo previo:

Ainsi, ce très sage Roy retrait des voies d'ignorance, tout ainssi comme le champ non labouré et par longtemps esté en friche, rempli d'espines, sanz aucun bon fruit porter, et après, lui deffriché et coultivé de bonne semence, porte fruit meilleur et plus habondament que autre terre, cestui sage, de soy esrachiées toutes espines de vices, en lui voult enter toutes vertueuses plantes, dont le fruit s'ensuivi si bon et de tel santé après, comme nous dirons par ordre, que encore en dure la rassadiacion et odeur en maints royaumes (p. 47).

Del mismo modo había trabajado el rey sabio para escapar de la ignorancia de la juventud. Así, en el momento de ser coronado, Carlos estaba listo para volcar al terreno de la práctica lo aprendido hasta el momento y así cumplir con el recto actuar que le deparaba el oficio regio. En efecto, los frutos se recogerían durante su reinado, tal como puede apreciarse en el Livre des fais. Gracias a su virtuosismo político, el rey pudo resolver todos los conflictos que se le habían

17 “Or, comme assez ay dit devant, le sage roy Charles, après son couronnement, en jeune aage averti par l'administration de raison de ce qui estoit convenable à faire à bon chevalereux prince, selon l'ordre de son estre, auquel, comme droit pasteur apertient à garder ses ouailles, s'est son peuple et ses subgz y ouvry les yeuls de son entendement, regarda son peuple et royaume batu et désolé de longue et greveuse guerre, et encore chascun jour mengié et dévouré par grandes et excessives compaignies esparses en divers lieux en son royaume; meu de grant pitié, moult voulsist aviser comment, sans sang humain espendre, lequel, selon la saincte loy, on doit espargnier, ce baston et flayel peust estre osté de son royaume" (De Pizan, 2009, pp. 116-117).

18 “Pantes anthropoi tou eidenai horegontai physei”, Aristóteles, Metafísica, 1, 1, (980a).

19 “Or, regardons la soubtilleté de l'entendement de nostre prince, comment grandement s'estendy à comprendre et concepvoir toutes choses, tant spéculatives, comme ouvrables” (De Pizan, 2009, p. 203) 
presentado previamente en su regencia y que, en realidad, no eran más que los viejos problemas que venían impidiendo la centralización monárquica y el fortalecimiento del poder real.

A continuación, propongo tres ejemplos en los que la escritora deja ver los frutos de aquellos conocimientos incorporados por el rey en su juventud y sin los cuales toda tarea de gobierno estaba condenada al fracaso.

\section{“Dont le fruit s'ensuivi si bon et de tel santé après..."}

\section{El rey gran orator}

En primer lugar, las ciencias del lenguaje: gramática, dialéctica y retórica. Si la justicia estaba en la base del officium regis y si la misma se desarrollaba cada vez más por canales legales, era indispensable que el monarca manejase el latín y conociese la ley en primera persona:

ce seroit chose très convenable et pertinent aux causes des cas divers et particuliers dont la cognoiscence leur est imputée et de droit commise, de quoy ne peut avoir introduction des loys, se n'est par estranges expositeurs, tout par peresce d'un petit de temps souffrir l'excercitation et labour d'estude (De Pizan, 2009, pp. 43-44).

La escucha de casos y la derivación de una parte de ellos a otras instancias de justicia formaban parte de la agenda política del rey a lo largo de la jornada (De Pizan, 2009, pp. 61-65). Sin embargo, el conocimiento del derecho no solo le era útil al rey en sus actividades diarias sino que era capital para la resolución de asuntos que condicionaban el destino del reino. ¿Acaso el argumento legal esgrimido por el rey Sabio, basado en los principios de soberanía e inalienabilidad de la Corona, no había proporcionado la justificación para la impugnación del tratado de Bretigny? ${ }^{20} \mathrm{~A}$ su vez, ¿no podría verse en el recuerdo de la ultrajante paz impuesta por Inglaterra en el relato de la autora un impulso a defender la soberanía y los bienes de la Corona de Francia? Respecto a este asunto, Christine relata una anécdota en la que Enrique de Lancaster se burlaba del rey francés a quien consideraba un simple abogado: "ce n'estoit qu'un advocat" (p. 242). No obstante, poco tiempo después los hechos se volverían contra aquella difamación, confirmando lo atinado de la respuesta que en aquella oportunidad dio el rey Sabio a sus heraldos tras enterarse de la burla del monarca inglés: "Et! Se nous sommes advocat, nous nous les bastirons tel plait, dont la sentence leur anuyera" (p. 242).

Decretada la sentencia, el tiempo le daría la razón. Si en 1360, como delfín, Carlos se había visto obligado a firmar la paz bajo las condiciones impuestas por el adversario, en 1369, como rey de Francia, recuperaría los bienes de la Corona y la soberanía sobre los territorios quitados por los ingleses. Si el argumento legal no bastó para convencer al rey inglés de ajustarse a derecho, por el contrario, sí fue eficaz para lograr el apoyo de los poderes de la época, en especial el del emperador Carlos IV. El 8 de enero de 1378, reunido con el emperador, el rey de Bohemia y distinguidos príncipes en el palacio del Louvre, Carlos V ofreció un brillante discurso con el objeto de lograr el aval para la impugnación del tratado de Bretigny y el consiguiente apoyo a la guerra contra Inglaterra. La elocuencia de sus argumentos y la belleza de sus oraciones terminaron por dejar maravillados a todos los presentes: 
Et assez d'aultres choses dist le Roy, qui longues seroient à dire, et par si bel ordre, si notable arrenge, lot dit que tous en furent esmerveilliez, et moult prisierent et louerent son grant sens et mémoire (p. 268).

Sin duda, el discurso fue efectivo. Al día siguiente, el emperador juró lealtad y ofreció auxilio al rey de Francia contra cualquiera de sus adversarios:

si vouloit que tous sceussent que lui, son filz le roy des Romains, ses autres enfens, et touz ses parens, aliez et amis, et toute sa puissance il vouloit et offroit au Roy estre tous siens contre toutes personnes, à aidier et garder son bien, honneur et royaume, et de ses enfens et frères et amis et adonc lui bailla un role, où ses amis et affins declairiez et nommez estoient, dont il se faisoit fort. Adonc le Roy le mercia moult gracieusement (p. 269).

En rigor, este episodio resalta la importancia de los conocimientos incorporados durante la juventud del rey Sabio y el modo en que estos fueron aplicados en la praxis política de gobierno. De ahí que no existiese mejor maestro de retórica en el Reino de Francia que el mismo rey francés:

Ot belle aleure, voix d'omme de beau ton; et avec tout ce, certes, à sa belle parleure tant ordenée et par si belle arrengé sanz aucune superfluité de parolle, ne croy que rethoricien quelquonques en lengue françoise sceust riens amender (p. 66).

\section{Un rey ausente del campo de batalla}

El segundo ejemplo de experiencia se relaciona con la guerra. El arte militar de los antiguos, legado a través del texto de Vegecio De Re militari, es tomado por la autora como modelo instructivo de la caballería. Como primer caballero del reino, la función del rey no estaba en el campo de batalla junto a las tropas sino en el área de estrategia bélica, organizando los cuerpos de caballería. Para justificar esta nueva función militar del rey, la escritora recurría a la metáfora plutarquiana del cuerpo (Blanchard, 1995). Así como el cuerpo y los miembros sufrían y se debilitaban cuando se golpeaba la cabeza, la captura o la muerte del príncipe en el campo de batalla podía conllevar a la perdición del reino. Por tal motivo, salvo ante un caso de extrema necesidad, el príncipe debía permanecer fuera del campo de batalla y, en su lugar, nombrar al mejor caballero del reino como jefe militar de sus ejércitos:

Encore fu sagement regardé, redoubtant la variacion de Fortune, que, tout ainssi que quant le chief est ferus le corps et les membres sont enfermez et douloreux, que aussi la prise ou mort du prince pourroit estre la perdicion de tous les subgiez, n'estoit mie expédient que sanz trop grant neccessité prince en propre personne alast en bataille; et pour ce avisa le prince à eslire un supérieur le plus esprouvé sage et expert en ordre d'armes, qui representant sa personne, eust la charge et admenistracion de toutes les ostz et assemblées d'icelle gent deffensable, et cellui appellerent prince de la chevalerie (De Pizan, 2009, pp. 110-111).

Este fue el modelo de Carlos V, quien gobernó desde los despachos del Louvre mientras sus hermanos y el gran "prince de la chevalerie", Bertrand du Guesclin, portaban las armas. Empero, si este soberano se mostraba seguro de llevar a la práctica las teorías favorables a los reyes ausentes en el campo de batalla era porque contaba con la experiencia previa, sufrida en carne propia, de un rey capturado en combate. ¿Acaso la desmoralización de las tropas tras la captura de Juan II en Poitiers en el fatídico año de 1356 no había sido vista como una de las causas de la derrota francesa? ¿O, asimismo, la posterior ausencia del rey y 
de los principales señores del reino no había desencadenado el estallido de una serie de conflictos -latentes- que el entonces delfín se había visto compelido a afrontar? Sin duda, de sus trágicos años como delfín, Carlos V había aprendido cuánto convenía al reino y a la dinastía que el soberano permaneciera fuera del campo de batalla. En este sentido, la elección en 1370 de Bertrand du Guesclin como condestable de Francia puede ser considerado como un verdadero acto de prudencia real, y como tal, indudablemente, no habría podido llevarse a cabo sin la deliberación necesaria puesta en marcha gracias a la inteligencia, memoria y previsión. De esta manera,

En toutes ces choses bien avisées par le Roy et son sage conseil, fu lors esleu à connestable de France le bon Breton chevalereux et preux messire Bertram De Clequin, et fu fait, le mecredi second jour du mois d'octobre, l'an mil .IIl'. LXX (p. 151).

\section{Una solución a la peste roja}

El tercer ejemplo se vincula al orden interno del reino. Como garante del bien común, Carlos V no podía permitir que a los padecimientos por la guerra se sumasen los daños causados por las compagnies -bandas de soldados desmovilizados- que continuaban creciendo de manera acelerada desde la batalla de Poitiers. Por ende, apenas coronado, el nuevo rey se dedicó a resolver el asunto usando su razón para extirpar aquella plaga devoradora de ovejas que azolaba su reino. Prudente, Carlos V se abocó a estudiar el medio por el cual deshacerse de las compañías evitando los derrames de sangre innecesarios “...moult voulsist aviser comment, sans sang humain espandre, lequel, selon la saincte loy, on doit espargnier, ce baston et flayel peust estre osté de son reaume" (De Pizan, 2009, p. 117). Y encontró la solución en el conflicto que por aquel entonces mantenían Pedro el Cruel y su hermano bastardo, Enrique de Trastámara, por la sucesión al trono castellano ${ }^{21}$. Aprovechándose de la situación que atravesaba la monarquía del sur, el astuto Carlos V planeó expulsar hacia el exterior un conflicto de carácter interno. De ahí que decidiese enviar a Castilla, como tropas auxiliares, las compañías que asolaban su reino bajo la excusa de otorgar ayuda a la casa de Trastámara. Gracias a la prudencia del rey Sabio, aquella población desempleada y perniciosa, que rompía con el orden y la paz interna, pudo ser finalmente canalizada hacia nuevos objetivos bélicos. De este modo, el monarca probó ser un "vray sage, deffendeur et gardeur de son peuple" (p. 118).

Si el miedo de Eduardo II a la muerte de Juan el Bueno fue verdadero, tal como sugiere el cronista Froissart, los hechos hasta aquí reseñados justifican en gran medida su temor de ver convertido en rey al joven delfín (Favier, 1980, pp. 56-57). Sin duda, y de acuerdo al relato de Christine, tras su coronación, los éxitos de este príncipe experto en todas las cosas útiles al gobierno se continuarían unos tras otros:

Ainssi, comme ouir povez, par grâce de Dieu, et desserte du sage roy Charles, aloit tous les jours croissant l'augmentacion de sa bonne fortune, qui au fueur de l'accroissement, plus reluisoient en lui à double vertu grâces et bonnes meurs, et plus en plus abondoit son bon sens qui le rendoit expert en toutes choses convenables (De Pizan, 2009, p. 184).

21 “Adonc, le pourveu roy Charles à juste cause ordEnna que son mareschal nommé Hernoul d’Endrehen, Bertran Du Clequin et autres chevetains conduisissent et menassent toute celle gent de compaigne en Espaigne, faire guerre au roy Pietre" (De Pizan, 2009, p. 117) 


\section{Reflexiones finales}

A estas alturas no existen dudas de que un rey no consagrado era una suerte de rey incompleto. No se entiende si no el esfuerzo del rey de Navarra por evitar la consagración de Carlos V durante la batalla de Cocherel (Autrand, 2009, pp. 450-453), el apuro de los príncipes de sangre por consagrar a Carlos VI a la edad de 12 años (Autrand, 1986, pp. 9-21), ni el ahínco de Carlos VII por consagrarse en un territorio completamente tomado por el enemigo inglés (Bove, 2009, p. 446). Si bien al arribar a Reims el rey ya contaba con las dos primeras condiciones para ser rey-era un elegido de Dios y era monarca por derecho hereditario-, le faltaba la tercera traditio, aquella de la consecratio. Era principalmente el rito de la unción, realizado por el arzobispo de Reims -Ungo te in regem ("Par cette onction, je te fais roi")- lo que lo convertía verdaderamente en rey (Le Goff, 2001, p. 21). Palabras y actos marcaban la transmisión del poder de Dios al soberano mediante la intercesión de la Iglesia. Por ende, si la consagración no hacía al rey, sí constituía un fundamento de origen divino ya que reforzaba el poder real al asociarlo con Dios y la Iglesia (Jackson, 1995, p. 247). Más que otros soberanos, Carlos V sustentaba su monarquía en dicha ideología eclesiástica, tal como puede verse en el manuscrito que conserva el recuerdo de su consagración, que él mismo mandó a confeccionar con el fin de fijar, para el futuro, la liturgia de consagración de los reyes y reinas de Francia. Allí, la centralidad del rito de la unción propiciado por el arzobispo de Reims resulta predominante en las miniaturas. Por lo demás, entre el millar de libros que contaba su biblioteca, el Ordo de Carlos V no era únicamente ubicable en la sección de liturgia sino en aquella correspondiente a las ciencias políticas (Demouy, 2016, p. 102). Este ordo compuesto de 38 miniaturas se caracterizaba por un realismo sin precedentes. Estas imágenes eran completadas tanto por el texto como por detalles precisos junto a la identificación de los personajes. Sin duda, dicho ordo era una parte fundamental dentro de la llamada religión monárquica. No obstante, a pesar de todas las evidencias, hemos visto lo alejada que estaba la teoría política de Christine de Pizan de dicho modelo.

En primer lugar, al priorizar la coronación sobre la unción, Christine le quitaba al ceremonial toda la carga eclesiástica proveniente de aquel acto sacramental que la leyenda atribuía al milagro de Clodoveo. Si de fundamentos sagrados se trataba, Christine de Pizan no necesitaba recurrir a la tradición de la religión real. Por el contrario, tenía otros elementos que, sin basarse en la intercesión de la Iglesia y en el milagro de la Sainte Ampoule, tenían la misma fuerza. Entre ellos, la escritora utilizó la filosofía de la sangre, los orígenes troyanos y la teología de la gracia. Asimismo, la fundamentación legal de la monarquía, aunque amparada en el derecho romano, también tenía una justificación religiosa, como el caso de la decretal Per Venerabilem y la idea de rey como vicario de Dios. Así, en el prólogo del Libro III, Christine de Pizan se apoyaba en la decretal para señalar que el rey de Francia no reconocía en lo temporal otro soberano que Dios:

Et Dieu loué! glorieux roy de France (...) vostre hault nom denonce sur tous princes mortelz, vous ne recognoissiez autre souverain que Dieu, comme il appert en la Decretale de enfens legittimez, per venerabilem (...) et que la refflambeur de vostre dyademe, qui naturelement reluit en marches de delices, precelle tous royaumes, par qui lueur toutes terres s'esclairent et se duisent à meurs, par qui aussi, si comme chascun scet, vassal de Dieu et le primier des roys vous estes appellés (De Pizan, 2009, pp. 196-197).

Producto del derecho canónico, la decretal Per Venerabilem anunciada por Inocencio III en 1202 signaba la independencia de Francia respecto al Imperio y el reconocimiento del poder del rey francés, quien, a partir de allí, no admitiría en su reino otro superior más que Dios (Bercé, 1997, p. 128). Gracias a esto, la escritora podía 
adjudicarle al monarca francés el título de vassal de Dieu et premier des rois, título originado en el derecho romano y presente en autores como Séneca y Vegecio (Kantorowicz, 2012, p. 119)

En base a estas consideraciones, el único interés que Christine guardaba respecto a la consagración estaba relacionado con su contenido político. El protagonismo de la corona por sobre la Sagrada Ampolla surtía el efecto de descartar el contenido religioso de la escena y de eliminar las instancias intermediarias. En este sentido, la ceremonia de consagración se presentaba como un suceso sin actores invitados, en donde los únicos protagonistas eran el rey y su corona, puesto que no existía mención alguna de los religiosos ni tampoco del resto de los participantes tradicionales del ritual. Al momento de ceñir la corona, el rey inauguraba su reinado e ingresaba al officium regis. Es en el marco de esta reflexión donde Christine propone una nueva especie de consagración real, al inscribir la consagración dentro del ciclo natural de las edades del hombre. A su vez, este modelo le permite a la autora plantear dos cuestiones de suma importancia en su pensamiento. En primer lugar, la distinción entre función regia y cuerpo natural del rey. En segundo lugar, las ideas de virtud política y de responsabilidad en el ejercicio del cargo, ambas cualidades presentes en el carácter del hombre maduro y ausentes en el del joven. En efecto, es sobre estas premisas que la escritora propone un tratamiento innovador de la consagración mediante la combinación de dos argumentos de raigambres distintas: la gracia de la tradición cristiana y la metafísica aristotélica. En su argumentación, ambos elementos son hábilmente combinados para sustentar, a su vez, dos pensamientos no siempre conciliables. En primer lugar, respecto a la defensa de la monarquía hereditaria, la creencia en la superioridad intelectual del rey francés por encima de todo hombre y soberano de su tiempo. En segundo lugar, la idea de que el ejercicio de gobierno dependía de la posesión de unas virtudes adquiridas antes que heredadas. De esta manera, la gracia aparecía como el atributo que dotaba al príncipe del intelecto más perfecto y que lo predisponía, más que a ningún otro hombre, al conocimiento y la adquisición de virtudes. No obstante, una vez dadas estas premisas, el resto dependía del príncipe, es decir, de su capacidad de persistir a fin de no salirse del camino marcado por la virtud. Por consiguiente, si la gracia era el punto de partida, no bastaba por sí sola para conducir al alma del príncipe hacia su principal fin: el gobierno. Para ello, era indispensable una educación tradicional que, junto a la experiencia, dotasen al príncipe de la prudencia y sabiduría del hombre maduro. Solo así, gracias a estos medios, el alma del futuro rey -envuelta en el cuerpo grosero de la juventud- podía alcanzar su fin primero, que no era otro que el gobierno del cuerpo político ${ }^{22}$. Este encuentro, simbolizado en el príncipe coronado, indicaba que el nuevo rey asumía el officium regis con las virtudes necesarias para ejercerlo. Ciertamente, si la sabiduría y la prudencia eran las garantías del buen gobierno, no era posible que asumiese un príncipe que careciese de ellas. Por otra parte, al hacer del rey un hombre maduro antes de tiempo, Christine evitaba los argumentos que hacían de la juventud del rey un criterio para sostener las regencias. De este modo, se alineaba con la ordenanza real de 1374 que rebajaba a los 14 años la edad de mayoría regia. Esta medida, que Christine consideraba un acto de prudencia real, buscaba fortalecer la monarquía y evitar así las regencias y el avasallamiento de poder por parte de los príncipes y nobles del reino (De Pizan, 2009, pp. 204-207). Por consiguiente, la teoría de la consagración elaborada por Christine era funcional a la ley sancionada por Carlos $\mathrm{V}$ desde el momento en que eliminaba las posibles objeciones de los príncipes de sangre, quienes, amparándose en la juventud e ignorancia del joven rey, buscaban excluirlo del officium regis. Finalmente, puede concluirse que como rito político la coronación carecía del significado milagroso del ritual eclesiástico. La intermediación 
de la Iglesia no era ya necesaria. Por el contrario, la escritora concebía un único protagonista y un único emblema, cuya unión marcaba la inauguración de un nuevo reinado: el rey y su corona. Este rey no debía su posición al milagro de la Iglesia, sino a su conocimiento, producto de la educación y de un intelecto sutil. En aquel mundo profano, movido por las acciones contingentes de los hombres, era poco conveniente la figura de un rey salido de la configuración eclesiástica. Por el contrario, las virtudes políticas adquiridas por medio de la ciencia y la experiencia resultaban las más adecuadas para gobernar. Si la consagración por el óleo celeste convertía al rey en un hombre nuevo, que compartía los atributos de la divinidad, el rey de Christine parecía atravesar una conversión de nuevo cuño. Allí no existía óleo santo ni sangre milagrosa que dotasen al monarca de las virtudes de gobierno. Rey consagrado por la phronesis, solo la aplicación de dicha virtud en el ejercicio diario de gobierno era la garantía del bienestar general del reino y la confirmación del recte agere requerido por la función real. 


\section{Bibliografía}

» Aristóteles. (1988). Política (Trad. M. García Valdés). Madrid: Gredos.

"Aristóteles. (2010). Acerca del Alma (Trad. M. D. Boeri). Buenos Aires: Colihue.

" Autrand, F. (1986). Charles VI. La folie du roi. París: Fayard.

" Autrand, F. (1994). Charles V. París: Fayard.

» Autrand, F. (2009). Christine de Pizan: Une femme en politique, París: Fayard.

》 Beaune, C. (1985). Naissance de la nation France. París: Gallimard.

» Bercé, Y-M. (Ed.). (1997). Les monarchies. París: Presses Universitaires de France.

» Blanchard, J. (1995). Répresentation, Pouvoir et Royauté à la fin du Moyen Âge, Actes du colloque organisé par l'Université du Maine le 25 et 26 mars 1994. París: Picard.

» Bove, B. (2009). Le temps de la guerre de Cent Ans (1328-1453). París: Belin.

»De Pizan, C. (2009). Le Livre des fais et bonnes meurs du sage roy Charles V. Texte original intégral du manuscrit BnfFr. 10153 (Ed. N. Desgrugillers). Clermont-Ferrand: Paleo.

"Demouy, P. (2016). Le sacre du roi. Estrasburgo: La Nuée Bleue.

" Favier, J. (1980). La Guerre de Cent Ans. París: Fayard.

» Jackson, R. (1995). Le pouvoir monarchique dans la cérémonie du sacre et couronnement des rois de France. En J. Blanchard (Ed.), Répresentation, Pouvoir et Royauté à la fin du Moyen Âge, Actes du colloque organisé par l'Université du Maine le 25 et 26 mars 1994 (237-251) París: Picard.

» Kantorowicz, E. H. (2012). Los dos cuerpos del rey. Un estudio de teología política medieval. Madrid: Akal.

" Le Goff, J. (2001). La structure et le contenu idéologique de la cérémonie du sacre. En J. Le Goff, E. Palazzo, J. C. Bonne y M. N. Colette (Eds.), Le Sacre royal à l'époque de Saint Louis d'après le manuscrit latin 1246 de la BNF (19-35). París: Gallimard.

" Molenaer, S. (1899). Li livres du gouvernement des rois: a XIIIth Century French Version of Egidio Colonna's Treatise De Regimine Principum. Nueva York: Macmillan.

" Ribémont, B. (2000). Le regard de Christine de Pizan sur la jeunesse (à propos du Charles V). Cahiers de recherches médiévales [en línea], 7, 255-26o. https://doi.org/10.4000/ crm.904

»Rodriguez, J. (2016a). Filiaciones cruzadas. El uso selectivo de la materia troyana y la tradición veterotestamentaria para la construcción del ideal monárquico en la obra de Christine de Pizan. En Pégolo, L. y Neyra, V. (Eds), Un milenio de contar historias. Los conceptos de ficcionalización y narración de la Antigüedad al Medioevo (237-251). Buenos Aires: Facultad de Filosofía y Letras.

" Rodriguez, J. (2016b). Una nueva identidad para el rey. La phronesis real en la teoría política de Christine de Pizan. Cuadernos Medievales, 21, 121-135.

» Rodriguez, J. (2019). El lenguaje político de la juventud: presente y futuro de un reino en el Livre des fais et bonnes meurs du sage roy Charles V de Christine de Pizan. Exlibris, 8, 73-89. 